\title{
GEOSUL
}

\section{TRANSFORMAÇÕES NO MERCADO DE TRABALHO CATARINENSE: A REALIDADE DA JUVENTUDE ${ }^{1}$}

\author{
Ivo Marcos Theis ${ }^{2}$ \\ Luis Claudio Krajevski ${ }^{3}$ \\ Daniel Rodrigo Strelow ${ }^{4}$ \\ Tatiane Thaís Lasta ${ }^{5}$
}

\begin{abstract}
Resumo: O desemprego e a informalidade tornaram-se elementos fundamentais para a sobrevivência do modelo vigente e a juventude é um dos segmentos que mais sofre com estes males. A década de 1990 é marcada pelo advento das políticas neoliberais, as quais promoveram diversas transformações no mundo do trabalho. Como consequência o Brasil e o Estado de Santa Catarina também sofreram os efeitos destas transformações. Assim, o objetivo deste artigo é construir um breve diagnóstico sobre o jovem, o mercado de trabalho e sua realidade no Estado de Santa Catarina. Aqui se privilegiou a ideia de como a juventude, ou uma grande parte dela, se depara frente às expressivas dificuldades quando de sua inserção no mercado de trabalho. Estas dificuldades se revelam nos índices de desemprego, na informalidade, nas baixas remunerações, entre outras formas de precarização existentes nas relações de trabalho.
\end{abstract}

Palavras-chave: Mercado de trabalho; Juventude; Santa Catarina.

\section{TRANSFORMATIONS IN THE SANTA CATARINA LABOR MARKET: THE REALITY OF YOUTH}

\begin{abstract}
Unemployment and informality have become fundamental to the survival of the current model and youth is one of the segments that suffers most from these evils. The 1990s is marked by the advent of neoliberal politics, which promoted several changes in the working world. As a result Brazil and the State of Santa Catarina also suffered the effects of these changes. The objective of this article is to build a brief diagnosis of the young, the labor
\end{abstract}

\footnotetext{
${ }^{1}$ Este artigo resulta de versões e trabalhos anteriores apresentados. O primeiro trabalho foi apresentado junto ao V Simpósio de Lutas Sociais na América Latina, em Londrina/PR, entre os dias 10 a 13 de setembro de 2013. O segundo é resultado de trabalho aprovado no XXI Congresso Brasileiro de Economia, realizado entre os dias 09 a 11 de setembro de 2015, em Curitiba/PR. Os autores agradecem pelas sugestões recebidas em ambas as oportunidades, mas, estão cientes de que cabe apenas a eles a responsabilidade pelo resultado final.

${ }^{2}$ Doutor em Geografia pela pela Universität Tübingen (Alemanha), bolsista de Produtividade em Pesquisa/CNPq. Professor e Pesquisador do Programa de Pós-Graduação em Desenvolvimento Regional/ [PPGDR] Universidade Regional de Blumenau (FURB).

${ }^{3}$ Doutorando pelo Programa de Pós Graduação em Desenvolvimento Regional da Universidade Regional de Blumenau (FURB). Mestre em Desenvolvimento Econômico pela Universidade Federal do Paraná (UFPR) Docente na Universidade Federal da Fronteira Sul (UFFS)

${ }^{4}$ Mestre em Desenvolvimento Regional pelo Programa de Pós-Graduação em Desenvolvimento Regional da Universidade Regional de Blumenau (FURB). Graduação em Ciências Econômicas pela FURB (2013). Integrante do Núcleo de Pesquisas em Desenvolvimento Regional (NPDR). Docente na Universidade do Estado de Santa Catarina (UDESC).

${ }^{5}$ Doutoranda e Mestre em Desenvolvimento Regional pelo Programa de Pós-Graduação em Desenvolvimento Regional da Universidade Regional de Blumenau (FURB). Graduação em Ciências Econômicas pela FURB (2013). Integrante do Núcleo de Pesquisas em Desenvolvimento Regional (NPDR).
} 
market and its reality in the state of Santa Catarina. Here we focused on the idea of how youth, or a large part of it, comes across the face of significant difficulties upon their insertion into the labor market. These difficulties are revealed in rates of unemployment, informality, the low pay and other forms of existing precariousness in labor relations.

Keywords: Labor market; Youth; Santa Catarina

\section{TRANSFORMACIONES EN EL MERCADO LABORAL CATARINENSE: LA REALIDAD DE LA JUVENTUD}

Resumen: El desempleo y la informalidad se han convertido en elementos fundamentales para la supervivencia del modelo vigente y la juventud es uno de los segmentos que más sufre con estos males. La década de 1990 está enmarcada por la llegada de las políticas neoliberales, las cuales promovieron diversas transformaciones en el mundo del trabajo. Como resultado, Brasil y el Estado de Santa Catarina también sufrieron los efectos de estas transformaciones. Por lo tanto, el objetivo de este artículo es construir un breve diagnóstico sobre el joven, el mercado laboral y su realidad en el Estado de Santa Catarina. Aquí se privilegió la idea de cómo la juventud, o una gran parte de ella, se enfrenta a las expresivas dificultades al incorporarse al mercado laboral. Estas dificultades se revelan en los índices de desempleo, en la informalidad, en las bajas remuneraciones, entre otras formas de precarización existentes en las relaciones laborales.

Palabras clave: Mercado laboral; Juventud; Santa Catarina

\section{INTRODUÇÃO}

Não há mais dúvidas de que a sociedade atual é pulsada por significativas desigualdades econômicas e sociais. Tal realidade é característica indispensável para o desenvolvimento do modo de produção capitalista, ou seja, as disparidades se fazem necessárias tanto para a sobrevivência como para o fortalecimento do modelo. Às maiorias desprivilegiadas, "do andar de baixo", apenas resta conviver diariamente com seus direitos mais básicos negados, como alimentação, trabalho, saúde, educação e tantos outros. Essa situação pode ser analisada como produto de um processo denominado de desenvolvimento desigual. Este sustenta que as desigualdades são produzidas pelo próprio modo de desenvolvimento vigente, observadas na diferença explícita das paisagens de regiões desenvolvidas e subdesenvolvidas. E, conforme nos recomenda um importante geógrafo da atualidade, é a acumulação do capital com bases no livre mercado que produz as diferenciações geográficas em termos de riqueza e poder (Harvey 2004). 
Infelizmente, grandes parcelas da população são excluídas diariamente e as disparidades sociais parecem ser tratadas como algo natural. A coexistência das desigualdades socioeconômicas, do descaso das elites e dos governantes se alia à ausência de garantia dos direitos fundamentais gerando, por consequência, exclusão social e violações de direitos. É a partir da década de 1990, com predomínio das políticas neoliberais, que se tem agravado o quadro de desigualdades, intensificando um cenário de desintegração social. O fato é que "a lógica deste modelo tem transformado pessoas e relações humanas em mercadorias" (Holloway 2003). De tal forma que, em uma sociedade sustentada por uma estrutura intrinsecamente desigual e excludente, alarga-se o desemprego e a precarização das relações de trabalho. Sendo que estas situações aparecem na forma da informalidade, ou seja, trabalho sem carteira assinada, em tempo parcial ou determinado, em situações de elevada rotatividade, em regime de terceirização e tantos outros (Oliveira; Mattoso 1996).

Para se ter uma ideia, nosso país é constituído por 48 milhões de habitantes entre 15 a 29 anos, dos quais 34 milhões encontram-se na faixa etária entre 15 a 24 anos. Os jovens enfrentam elevadas taxas de rotatividade, principalmente por ocuparem postos de trabalhos mais precários, muitas vezes de caráter temporário, pois não dispõem de outras alternativas. Não obstante, constituem o grupo etário mais desfavorecido pelas condições de trabalho, pois apresentam altas taxas de desemprego e informalidade, baixos rendimentos e ausência de proteção social (DIEESE 2009). Segundo a Pesquisa Nacional por Amostra de Domicílios PNAD, do Instituto Brasileiro de Geografia e Estatística - IBGE, em 2006 os trabalhadores jovens ganhavam, em média, menos de metade do que ganhavam os adultos, sendo que 63\% destes não tinham carteira profissional assinada. Portanto, os jovens formavam a faixa etária mais vulnerável e desamparada em relação à segurança social.

Pochmann publicou diversos estudos e ensaios sobre a temática da juventude no Brasil com enfoque justamente no mercado de trabalho. De acordo com ele, "Os jovens, em especial, são atingidos decisivamente. De um lado pelo desemprego, já que a cada duas pessoas sem trabalho no Brasil, uma possui menos de 25 anos de idade. De outro, sem a perspectiva de mobilidade social ascendente, cresce, sobretudo entre os jovens, tanto a violência como a emigração da população com maior grau de escolaridade" (Pochmann 2004: 396). 
A juventude sempre foi um dos grandes motores das lutas por mudanças, seja no Brasil como no mundo afora. Muitos consideram a juventude como protagonista da transformação da sociedade, tornando-se assim um ator estratégico no desenvolvimento das nações. Daí então se reconhece a importância e a necessidade de aprofundar este debate e de se investigar ainda mais a realidade do jovem e seus desafios frente ao mercado de trabalho, além das desigualdades e dificuldades "sentidas na pele" por este segmento da sociedade. Assim sendo, o objetivo deste artigo é construir um breve diagnóstico sobre a juventude e o mercado de trabalho em Estado de Santa Catarina. Para lograr este intento, primeiramente faz-se uma (i) revisão bibliográfica dos principais conceitos acerca do tema juventude e mercado de trabalho; (ii) contextualiza-se as transformações no mercado de trabalho de Santa Catarina no contexto brasileiro; (iii) apresentam-se dados especificamente para o Estado de Santa Catarina.

Com relação ao método de abordagem, se considerou inicialmente que o mercado de trabalho catarinense vem passando por mudanças substanciais nos últimos tempos. A busca de compreensão deste processo exige um entendimento amplo, embora bem definido. Considera-se, por isso, a perspectiva dialética, que privilegia enfoques baseados na contradição e na produção de sínteses, como a abordagem mais ajustada à produção de respostas teoricamente significativas e empiricamente relevantes (Ritsert 1997). Quanto ao método de procedimento recorreu-se a pesquisa bibliográfica-documental. Dessa forma, num primeiro momento buscou-se realizar uma revisão e atualização bibliográfica dos termos juventude e mercado de trabalho. Tendo isso como ponto de partida, e considerando esses conceitos essenciais para a execução da pesquisa, num momento seguinte se realizou a coleta e análise de dados obtidos juntos a fontes oficiais. Para a coleta de dados e análises foram utilizados os dados disponíveis pelo PNAD/IBGE (tanto de 2006 como de 2013), além dos dados disponibilizados pela Secretaria de Estado da Assistência Social, Trabalho e Habitação (SST)/Diretoria de Trabalho e Emprego (DITE) do Estado de Santa Catarina. Apesar da existência de diferentes recortes, o objeto de análise compreende os jovens de 15 a 24 anos de idade.

As definições e parâmetros utilizados são definidos pelo IBGE. Neste sentido, entendese por PEA tanto os indivíduos "ocupados" como "desocupados", ou melhor, aqueles que estavam trabalhando no período da pesquisa e os que estavam procurando emprego. Outras 
variáveis objeto de análise foram: gênero, ocupação principal, emprego formal e informal, nível de escolaridade e local de exercício da atividade remunerada (urbana ou rural). Os dados coletados se referem ao Estado de Santa Catarina e o período escolhido permite observar como as mudanças mais recentes afetaram a situação da juventude e sua relação com o mercado de trabalho. Dessa forma, a partir dos dados coletados, tabulados e analisados, podese identificar a realidade do mercado de trabalho catarinense.

Para dar conta do objetivo proposto, o artigo está dividido nas seguintes seções: além desta seção de caráter introdutório, tem-se a seção seguinte, a qual apresenta breves conceitos para a compreensão do jovem e o mercado de trabalho. Na seção três, trata-se da contextualização das transformações no mercado de trabalho em nível mundial e brasileiro. Na quarta seção, são apresentados os dados do jovem e sua inserção no mercado de trabalho catarinense. E, finalmente, apresentam-se as considerações finais.

\section{JUVENTUDE E MERCADO DE TRABALHO: ALGUMAS CONCEITUAÇÕES IMPORTANTES}

Quando se debate a questão da juventude, existe a necessidade de se contextualizar e definir alguns conceitos. Diante disso, esta seção tem a finalidade de discutir o termo juventude e o mercado de trabalho, suas implicações e algumas considerações iniciais. Com relação a definição de jovem, esta é subjetiva e possui diferentes recortes, tais como o da Organização Internacional do Trabalho - OIT, da Secretaria Nacional da Juventude, do DIEESE, entre outros. Segundo a Organização das Nações Unidas para a Educação, a Ciência e a Cultura - UNESCO, "O termo juventude refere-se ao período do ciclo da vida em que as pessoas passam da infância para a condição de adultos e durante o qual se produzem importantes mudanças biológicas, psicológicas, sociais e culturais, que variam segundo as sociedades, as culturas, as etnias, as classes sociais e gênero.” (UNESCO 2004: 23).

Ao analisarmos estudos mais antigos sobre o tema da juventude na década de 1960, por exemplo, "jovens" eram considerados somente os estudantes ou universitários. O restante desse segmento era "invisível", como a juventude trabalhadora, a juventude da periferia, a juventude do campo. Somente a partir da década de 1990 que a juventude entra na pauta pública, em decorrência da preocupação com os problemas vividos pela juventude como 
violência, envolvimento com o mundo da criminalidade, exclusão e desemprego. Por outro lado, apareciam organizações e movimentos juvenis das mais variadas formas, que passaram a denunciar as condições de vida que enfrentavam (Freitas 2007).

Neste artigo, entende-se a juventude como uma categoria social. E isso faz da juventude mais do que uma faixa etária, o que não significa um grupo coeso ou uma classe de fato. A juventude torna-se assim: a) uma representação sociocultural (a juventude é uma concepção, representação ou criação simbólica, fabricada pelos grupos sociais ou pelos próprios indivíduos tidos como jovens, para significar uma série de comportamentos e atitudes a ela atribuídos); b) uma situação social (a juventude é uma situação vivida em comum por certos indivíduos). O jovem de que aqui se fala então, é definido social e culturalmente. Não é mais criança, nem é adolescente (Dick 2003: 26). Diante disso, este trabalho considera como jovem, o grupo de pessoas que possui idade entre 15 e 24 anos de idade.

O modo de produção capitalista afastou o homem das ferramentas necessárias para a sua subsistência. Neste sentido, alguns poucos passaram a deter os fatores de produção e aqueles que não tiveram esta condição passaram a vender sua força de trabalho como único meio para sobreviver. A busca por atividades que permitam a subsistência aliada a demanda por trabalhadores constitui o denominado mercado de trabalho. As condições da vida humana levam as pessoas a buscar uma colocação neste mercado de trabalho que lhe possibilitem sua sobrevivência, além de implicar nas expectativas referentes a "um futuro melhor". Ele tem se tornado, ao longo do tempo, mais dinâmico, flexível e especializado. Desta forma, os seres humanos têm se inserido no mercado de trabalho cada vez mais cedo. Assim, os jovens acabam constituindo um significativo segmento dos trabalhadores que efetivamente trabalham ou estão em busca de uma ocupação.

O universo a respeito dos estudos e pesquisas sobre o mercado de trabalho considera, como ponto de partida, a População em Idade Ativa - PIA. A PIA considera as pessoas com dez anos de idade ou mais (IBGE 2015). A PIA pode ser dividida em três segmentos: ocupados, desocupados e não economicamente ativos. Ocupados são aqueles que, no momento da pesquisa, exercem atividade remunerada ou desenvolvem atividades não remunerada em condições específicas (trabalho realizado em atividades de familiares). Os desocupados compreendem as pessoas que não estão ocupadas, mas que estão à procura de uma atividade remunerada, isto é, estão à procura de emprego, sendo usual o período de 
referência de trinta dias (IBGE 2015). O pessoal ocupado acrescido do pessoal desocupado constitui a População Economicamente Ativa - PEA (SEADE 2015). As pessoas não economicamente ativas são aquelas que não se encontram nem ocupadas nem desocupadas no período analisado.

No caso brasileiro, apesar de algumas políticas públicas terem como objetivo estimular a entrada do jovem no mercado de trabalho, esta inserção ainda não atinge os resultados esperados, além de ser permeada de desigualdades significativas. As políticas neoliberais e a reestruturação produtiva a partir da década de 1990 contribuíram, sobremaneira, para a redução de oportunidades para os jovens no mercado de trabalho. Não obstante, as dificuldades enfrentadas por parte da juventude brasileira, tais como pouco tempo de estudo, baixa qualificação, inexperiência, remuneração inferior, entre outros, contribuem para a existência de disparidades significativas no mercado de trabalho em que o jovem está inserido. Obviamente, há distorções provocadas por áreas de abrangência e regiões examinadas, número de anos de ensino formal, atividades econômicas, questões de gênero, faixa etária, entre outros, além da situação de emprego formal ou informal.

A existência de fontes de pesquisa e metodologias diferentes, além da não padronização das faixas etárias em que o jovem é inserido, dificulta uma análise mais elaborada e precisa sobre a participação da juventude no mercado de trabalho. Apesar de estudos recentes trazerem dados e informações a respeito, diagnósticos mais elaborados, que considerem o impacto das políticas públicas voltadas a juventude brasileira e catarinense, ainda necessitam serem produzidos. Evidentemente, tal situação não impede a análise do jovem e o mercado de trabalho catarinense.

\section{AS TRANSFORMAÇÕES NO MUNDO DO TRABALHO}

Na lógica capitalista, o trabalhador nada mais é que força de trabalho a serviço da valorização do capital. Seu limite de tempo de descanso é determinado pela necessidade de um maior dispêndio diário da força de trabalho. A produção capitalista necessita prolongar a jornada de trabalho e, ao fazê-la, produz não apenas a atrofia desta, mas seu aniquilamento prematuro, ou seja, produz mais e encurta o tempo de vida do trabalhador. Sua rápida substituição é resolvida por uma população que se encontre com disposição de trabalhar, mas 
que, sejam quais forem os motivos, não se encontram empregados (o chamado Exército Industrial de Reserva, de Marx). Pouco importa ao capital a saúde do trabalhador ou seu tempo de vida. Tal postura se relaciona menos com a pretensão do capitalista individual, mas com as leis da livre concorrência impostas à classe capitalista. Essa "pouca importância" ao trabalhador só se modifica caso o capital seja coagido pela sociedade a tal. Tanto que o estabelecimento de uma "jornada normal" de trabalho é fruto de uma "luta multissecular entre capitalista e trabalhador", ou seja, da luta de classes (Marx 1985: 215).

Conforme Harvey (1996), é a partir da década de 1970 que as grandes mudanças ocorreram, seja nas práticas econômicas, políticas e culturais. Isso não significa o começo de uma sociedade pós-capitalista, mas sim, representa um alerta quanto a superação do modelo de acumulação taylorista-fordista. Este mesmo autor ainda separa as transformações ocorridas em dois períodos: o primeiro partir de 1910 e o segundo, de 1973 em diante. No primeiro, a sustentação do sistema capitalista se dava ao fordismo-taylorismo e, mais tarde, com o keynesianismo. Os principais motores da acumulação de capital eram produção por escalas, linha de produção, disciplina, organização do trabalho por tarefas, funções repetitivas. O fordismo-taylorismo funcionou até 1973, a partir daí ocorre um período de recessão do qual se inicia um novo ciclo do capital, batizado de período de "acumulação flexível”, marcado por momentos como a crise mundial nos mercados imobiliários, aumento do preço do petróleo e profunda crise fiscal. Esse processo de "acumulação flexível” se apoiou:

"[...] na flexibilidade dos processos de trabalho, dos mercados de trabalho, dos produtos e padrões de consumo. Caracteriza-se pelo surgimento de setores de produção inteiramente novos, novas maneiras de fortalecimento dos serviços financeiros, novos mercados e, sobretudo, taxas altamente intensificadas de inovação comercial, tecnológica e organizacional. A acumulação flexível envolve rápidas mudanças dos padrões do desenvolvimento desigual, tanto entre setores como entre regiões geográficas, criando, por exemplo, um vasto movimento no emprego no chamado 'setor de serviços' bem como conjuntos industriais completamente novos em regiões até então subdesenvolvidas.” (Harvey 1996: 140).

O resultado de tais mudanças foi uma nova estruturação do mercado de trabalho, onde trabalhadores formais, com carteira assinada, tornaram-se minoria. Dessa maneira, os custos dessas transformações acabaram pagos justamente pela "classe que vive do trabalho", ou seja, a conta sobrou para o trabalhador nas mais diferentes formas como a informalidade, baixos rendimentos, desemprego e precarização (Antunes 2002). 
As mudanças sociais advindas dos projetos neoliberais dos governos Tatcher e Reagan, das décadas de 1970 e 1980, embarcaram num projeto político amplo e inclusivo que excluía outras opções. No Reino Unido com Tatcher no poder, com o famoso discurso do "There is no alternative", se deu a mercantilização dos direitos e da vida, com a ideia de que não havia outra alternativa a não ser o "receituário" neoliberal. Essa "alternativa Tatcheriana" individualizante foi a base para que se estabelecesse e se oportunizasse a ausência de outras alternativas ao desenvolvimento do modelo então proposto. Essa conjuntura foi truncando cada vez mais as ações de sindicatos e as organizações em defesa dos direitos dos trabalhadores (Beynon 1999).

A passagem do século XXI veio acompanhada de profundas e complexas transformações no modo de produção capitalista e no mundo do trabalho. A atual fase do modo de produção é expressa pelo domínio do capital financeiro, sendo esta "a etapa mais avançada do capitalismo porque nela a capacidade de mobilização dos capitais se transforma em uma força de supressão das barreiras tecnológicas e de mercado" (Chesnais 2005: 19). Parece certo afirmar que o processo de acumulação capitalista demanda, para sobreviver, que se mantenham altas taxas de desemprego, bem como, de desarticulação dos trabalhadores (ou seja, que se promova constantemente a precarização das relações de trabalho) (Mészáros 2002; Antunes 2002; Harvey 1996).

Não há como negar a atualidade dos elementos anteriormente apontados, principalmente no caso de um país periférico como o Brasil e, seguindo o cenário nacional, também em Santa Catarina. Na década de 1990, com o advento do neoliberalismo, os impactos foram, e continuam sendo, sentidos pelo Brasil e por toda a América Latina, pois ocorreu no período "uma desconcentração do poder do Estado nacional, reorientado por reformas em favor do mercado" (Ramalho, Oliveira 2013: 211-212).

As mudanças ocorridas em nível mundial provocaram alterações na estrutura da economia brasileira, com efeitos significativos sobre o desempenho econômico e, sobretudo, sobre as relações de trabalho. Tais modificações implicaram na redução da participação do emprego industrial e o crescimento do setor terciário. Paralelo a isso, se intensificou a precarização das relações de trabalho, refletida no aumento do emprego informal. Atualmente, além do desemprego, vivenciamos diferentes maneiras, novas e precárias, de contratação dos 
trabalhadores. Tais relações favorecem o capital, principalmente porque o poder de negociação dos trabalhadores é cada vez mais reduzido (Antunes e Alves 2004).

Ao longo dos anos 1990 o país sofreu com a adoção de políticas neoliberais, iniciadas no governo Collor e acelerada posteriormente com o governo de Fernando Henrique Cardoso. A economia brasileira acabou marcada por uma rápida abertura econômica, valorização da moeda nacional com base no aumento das taxas de juros, privatização de estatais e por consequência, aumento do desemprego, (Pochmann 1999). Assim, nessa "década neoliberal" o mercado de trabalho brasileiro sofreu grandes transformações e acabou marcado pela intensidade na precarização das relações de trabalho, pela flexibilização e pela terceirização. De acordo com Mattoso, "Na verdade, o desemprego e a precarização das condições e relações de trabalho que se observam ao longo dos anos 90, e mais intensamente no primeiro governo de Fernando Henrique Cardoso (1995-98), são um fenômeno de amplitude nacional, de extraordinária intensidade e jamais ocorrido na história do país” (Mattoso 2000).

O pacote neoliberal implementado no governo de Fernando Henrique Cardoso foi essencial para que as condições macroeconômicas propícias para um novo e instável ciclo de acumulação no Brasil fossem criadas. Alves é enfático ao debater sobre os anos 90: "é a década da inserção subalterna do Brasil na mundialização do capital por meio de políticas neoliberais que acentuaram a lógica destrutiva do capital no país” (Alves 2002: 71).

O cenário exposto, portanto, colaborou para que se constituísse uma onda de insegurança no mercado de trabalho brasileiro. E, mais uma vez, quem sentiu os efeitos maléficos destas mudanças foram os trabalhadores. As consequências foram altas taxas de desemprego, as novas e intensas formas precárias de contratação, baixos salários, entre outras. A restruturação do capital acompanhada de políticas neoliberais interferiu diretamente na realidade produtiva, na forma de ser e na vida dos trabalhadores. Nas formações periféricas como é o caso do Brasil, se observa tanto um aumento no contingente de desempregados no setor primário, como também uma elevação na informalidade no setor terciário. Cabe perguntar: Como a juventude se insere nesse contexto?

Um estudo realizado pelo DIEESE em 2001 aponta que o surgimento de uma onda de desemprego e insegurança no mercado de trabalho brasileiro fez com que os jovens que estavam se inserindo no mercado de trabalho perdessem empregos formais. Ainda sobre a questão da juventude no Brasil, segundo estudos realizados pelo mesmo instituto, na primeira 
década dos anos 2000 a taxa de desemprego aberto da população adulta diminuiu levemente (6,1\%, em 2005), mas o desemprego dos jovens aumentou (19,1\%, em 2005). O aumento na quantidade de jovens se deu de forma diferenciada da evolução do restante da população. Sobretudo em relação ao desemprego, que cresceu muito mais entre os jovens se comparado às demais faixas etárias. Em 2005, por exemplo, a quantidade de jovens desempregados chegou a $107 \%$ superior a de 1995, enquanto o desemprego para a população economicamente restante do país foi 90,5\% superior nos últimos dez anos (Pochmann 2007).

\section{JUVENTUDE E TRABALHO EM SANTA CATARINA - RESULTADOS E DISCUSSÕES}

Apesar de Santa Catarina ser identificada muitas vezes como um Estado que apresenta indicadores superiores as demais unidades da federação, as desigualdades não deixam de existir. Pelo contrário, observa-se que as condições do jovem no mercado de trabalho catarinense são semelhantes às existentes no cenário nacional. Da PEA total de Santa Catarina em 2006, os jovens (considerando o universo de pessoas entre 15 e 24 anos) correspondiam a 22,93\%. Já em 2013, essa proporção sofreu leve queda, passando a 20,16\% (IBGE/PNAD 2006; 2013).

\section{TABELA 1: DADOS PEA E NÃO PEA PARA A POPULAÇÃO JOVEM DE SANTA CATARINA (15 A 24 ANOS), PERÍODO DE 2006 A 2013.}

\begin{tabular}{cccccc}
\hline \multirow{2}{*}{ Anos } & $\begin{array}{c}\text { Pop. 15 a 24 } \\
\text { anos }\end{array}$ & \multicolumn{2}{c}{ Economicamente ativas } & \multicolumn{2}{c}{ Não economicamente ativas } \\
\cline { 2 - 6 } & Total & Total & \% do total & Total não & \% do total \\
& & PEA & PEA & PEA & PEA \\
\hline $\mathbf{2 0 0 6}$ & 1.078 .155 & 766.632 & $71,11 \%$ & 311.523 & $28,89 \%$ \\
\multirow{2}{*}{$\mathbf{2 0 1 3}$} & 1.079 .454 & 741.418 & $68,68 \%$ & 338.036 & $31,32 \%$ \\
\hline
\end{tabular}

Fonte: Elaborado pelos autores com base nos dados do IBGE/PNAD, 2006; 2013.

Em termos absolutos, conforme a tabela 1, houve crescimento da população entre 15 e 24 anos no período 2006-2013 em 0,12\%. Porém, a PEA juvenil sofre uma queda, pois em 2006, 71,11\% dos jovens eram economicamente ativos, ao passo que em 2013, 68,68\% se 
enquadravam nesta categoria, o que corresponde a uma queda de 3,28\%. Evidentemente, o grupo de jovens não economicamente ativos apresentou um leve crescimento.

Outro dado importante leva em consideração a demonstração dos jovens na PEA de acordo com o local em que trabalham (se área urbana ou rural). Em 2006, da PEA juvenil, 83,02\% estavam trabalhando ou procurando emprego nos espaços urbanos de Santa Catarina, enquanto 17,98\% dos jovens o faziam nos espaços rurais. Já em 2013, houve uma elevação no mercado de trabalho juvenil nos espaços urbanos: os jovens trabalhadores das cidades passaram a $88,38 \%$, enquanto os do campo representam apenas $11,63 \%$. Isso também é resultado do processo de concentração urbana e, ainda, do êxodo rural (IBGE/PNAD 2006; 2013). A dificuldade do jovem em permanecer no campo, aliada a atratividade dos grandes centros urbanos, faz com que o jovem recorra a migração do campo para a cidade de forma cada vez mais acentuada. Assim, para alterar esta migração faz-se necessário que os governos criem políticas públicas de estímulo a permanência dos jovens no interior do país.

Quanto a questão de gênero, observa-se no gráfico 1 a distribuição da PEA juvenil no período observado.

GRÁFICO 1: PEA DOS JOVENS DE 15 A 24 ANOS SEGUNDO GÊNERO - 2006 E 2013.

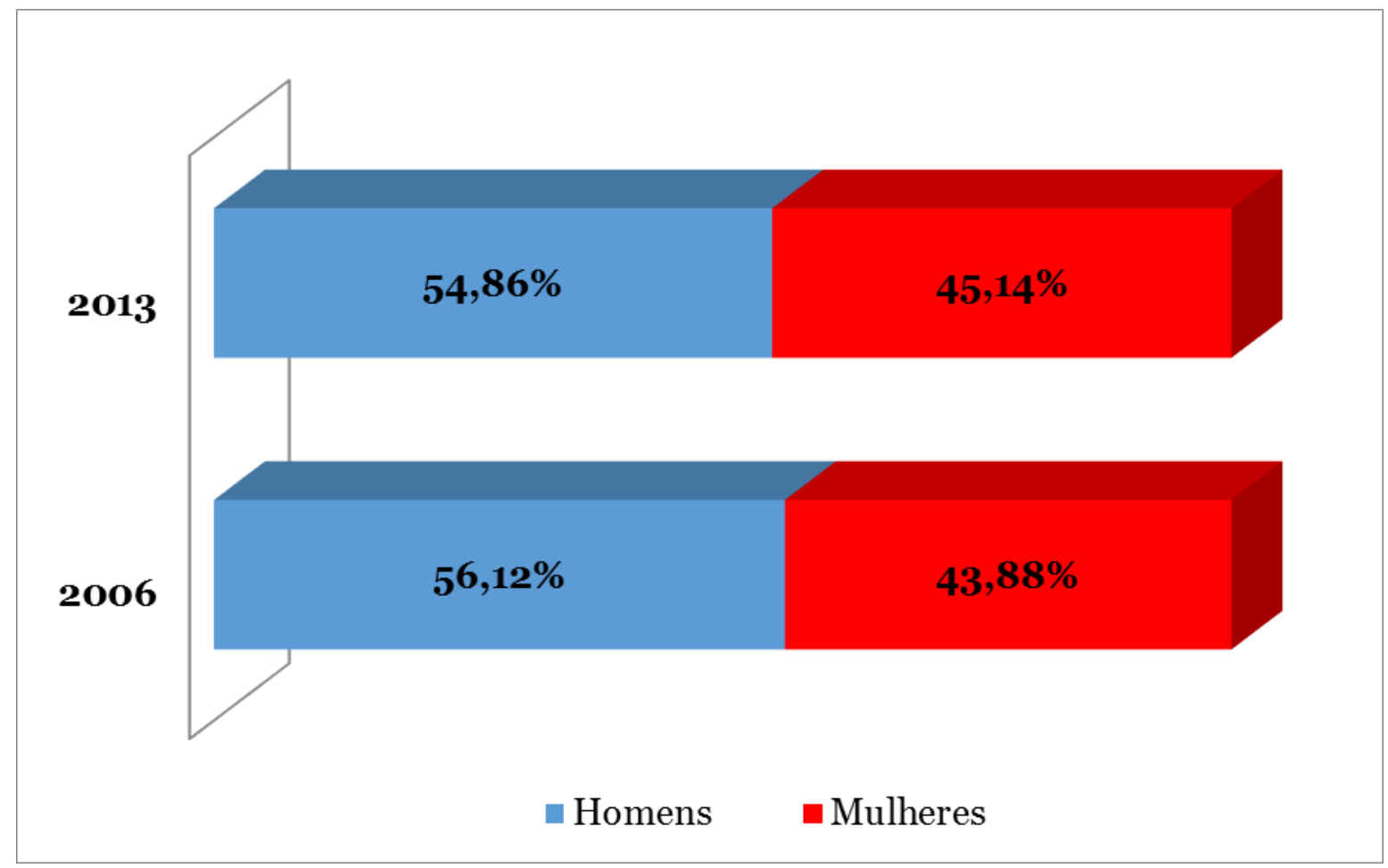


Fonte: Elaborado pelos autores com base nos dados do IBGE/PNAD, 2006; 2013.

Como se evidencia no gráfico 1 , os jovens do sexo masculino são maioria na PEA catarinense, tanto em 2006 (56,12\% ante 43,88\%) como em 2013 (54,86\% ante 45,14\%). Convém destacar que neste período a população feminina empregada, ou que estava à procura de emprego, experimentou um pequeno aumento, ao passo que a masculina obviamente diminuiu (IBGE/PNAD 2006; 2013). Tal situação pode apontar a presença cada vez mais forte das mulheres no mercado de trabalho (apesar das distorções ainda encontradas, como menor remuneração se comparadas aos homens). Quanto a ocupação dos jovens, é possível identificar as principais atividades econômicas na tabela dois (considerando a PEA).

TABELA 2: POSIÇÃO NA OCUPAÇÃO DOS JOVENS DE 15 A 24 ANOS (PEA 2006 E PEA 2013).

\begin{tabular}{|c|c|c|c|c|}
\hline \multirow{2}{*}{$\begin{array}{l}\text { Posição na ocupação no trabalho } \\
\text { principal }\end{array}$} & \multicolumn{2}{|c|}{ PEA 2006} & \multicolumn{2}{|l|}{ PEA 2013} \\
\hline & Quantidade & $\%$ & Quantidade & $\%$ \\
\hline Empregados & 524.603 & $68,4 \%$ & 592.591 & $79,9 \%$ \\
\hline Trabalhadores domésticos & 28.372 & $3,7 \%$ & 7.406 & $1,0 \%$ \\
\hline Conta própria & 39.373 & $5,1 \%$ & 47.813 & $6,4 \%$ \\
\hline Empregadores & 7.528 & $1,0 \%$ & 6.061 & $0,8 \%$ \\
\hline Não remunerados & 74.114 & $9,7 \%$ & 24.241 & $3,3 \%$ \\
\hline $\begin{array}{l}\text { Trabalhadores na produção para } \\
\text { o próprio consumo }\end{array}$ & 5.790 & $0,8 \%$ & 1.347 & $0,2 \%$ \\
\hline $\begin{array}{l}\text { Trabalhadores na construção para } \\
\text { o próprio consumo }\end{array}$ & 0 & $0,0 \%$ & 0 & $0,0 \%$ \\
\hline Não ocupada/desempregada & 86.852 & $11,3 \%$ & 61.959 & $8,4 \%$ \\
\hline TOTAL PEA & 766.632 & 100,00 & 741.418 & 100,00 \\
\hline
\end{tabular}

Fonte: Elaborado pelos autores com base nos dados do IBGE/PNAD, 2006; 2013.

Conforme descrito na tabela 2, a maioria dos jovens catarinenses da PEA encontravase na categoria de empregados, tanto em 2006 (68,4\%) como em 2013 (79,9\%), representando 
um incremento de $12,95 \%$. Não por acaso, quase todas as demais categorias experimentaram queda. $\mathrm{O}$ percentual dos jovens não ocupados/desempregados da PEA catarinense também caiu ao longo do período analisado. Se em 2006 era de 11,3\% (86.852 jovens), em 2013 passou a 8,4\% (61.959) (IBGE/PNAD 2006; 2013). A queda deste percentual pode indicar um bom sinal, mas ainda não é o ideal. Por exemplo, de acordo com SST/SINE/SC (2015), a taxa de desemprego da PEA adulta em 2013 foi de 3,2\%. Sem contar que, quanto menor a idade dos jovens, maior é a taxa de desemprego. Prova disso é que entre os jovens de 15 a 19 anos, essa taxa se eleva para $11,1 \%$. Isso mostra as dificuldades que os jovens encontram no mercado de trabalho. Além disso, quanto menor for os anos de experiência e ensino, menores serão os salários. Obviamente, a contratação de jovens com pouca qualificação acaba sendo uma estratégia das empresas visando a redução de custos.

Retomando a questão da PEA juvenil (15 a 24 anos), com relação à questão de gênero, o desemprego é um pouco maior entre as jovens. Em 2006, tanto em termos absolutos como em relativos, a taxa de desemprego era mais elevada para as mulheres jovens: 50.953 ou $15,15 \%$ estavam desempregadas, enquanto 35.899 (ou 8,34\%) jovens do sexo masculino estavam sem emprego. Em 2013 a situação melhorou consideravelmente, apesar de ainda ser desigual: em números absolutos, os jovens masculinos eram a maioria sem emprego (32.326 homens diante de 29.633 mulheres), mas em termos proporcionais as jovens ainda ostentavam uma taxa maior de desemprego: 8,9\% (ante 7,9\% dos homens) (IBGE/PNAD 2006; 2013).

A taxa de formalidade, conforme gráfico 2, vem aumentando ao longo dos anos. Em 2006, 63\% dos jovens catarinenses atuavam no mercado com carteira assinada, ao passo que $37 \%$ o faziam através da informalidade. Já em 2013, a taxa de formalidade entre os jovens passou a ser de 75\%, defronte à informalidade de 25\% (SST/SINE/SC, 2015). É um bom avanço, mas cabe alguns questionamentos. Afinal, 25\% dos jovens de Santa Catarina ainda atuam no mercado informal e, portanto, não tem seus direitos trabalhistas e previdenciários garantidos. A informalidade pode ser fruto de diversos fatores. Muitas unidades produtivas ainda atuam sem serem formalizadas. Possivelmente, parte destas iniciativas busca uma redução de custos com a mão de obra, sendo que os jovens constituem um perfil interessante para os empreendimentos que adotam esta estratégia (diminuição de custos). Não obstante, a dificuldade em obter o primeiro emprego provoca certa insegurança ao jovem. Diante disso este jovem, em virtude da inexperiência, acaba aceitando exercer uma atividade remunerada 
na informalidade, pois necessita obter renda e garantir a aquisição de certa experiência (mesmo que não comprovada). No entanto, algumas empresas utilizam deste artifício para explorar ainda mais os trabalhadores, permitindo uma maior taxa de mais-valia e, portanto, maior acumulação de capital. Afinal, os custos com a previdência (aliados a salários mais elevados) reduziriam a margem de lucro das empresas que utilizam deste subterfúgio.

GRÁFICO 2: EVOLUÇÃO DA TAXA DE INFORMALIDADE E DE FORMALIDADE DOS JOVENS EM SANTA CATARINA EM \% (2006 A 2013).

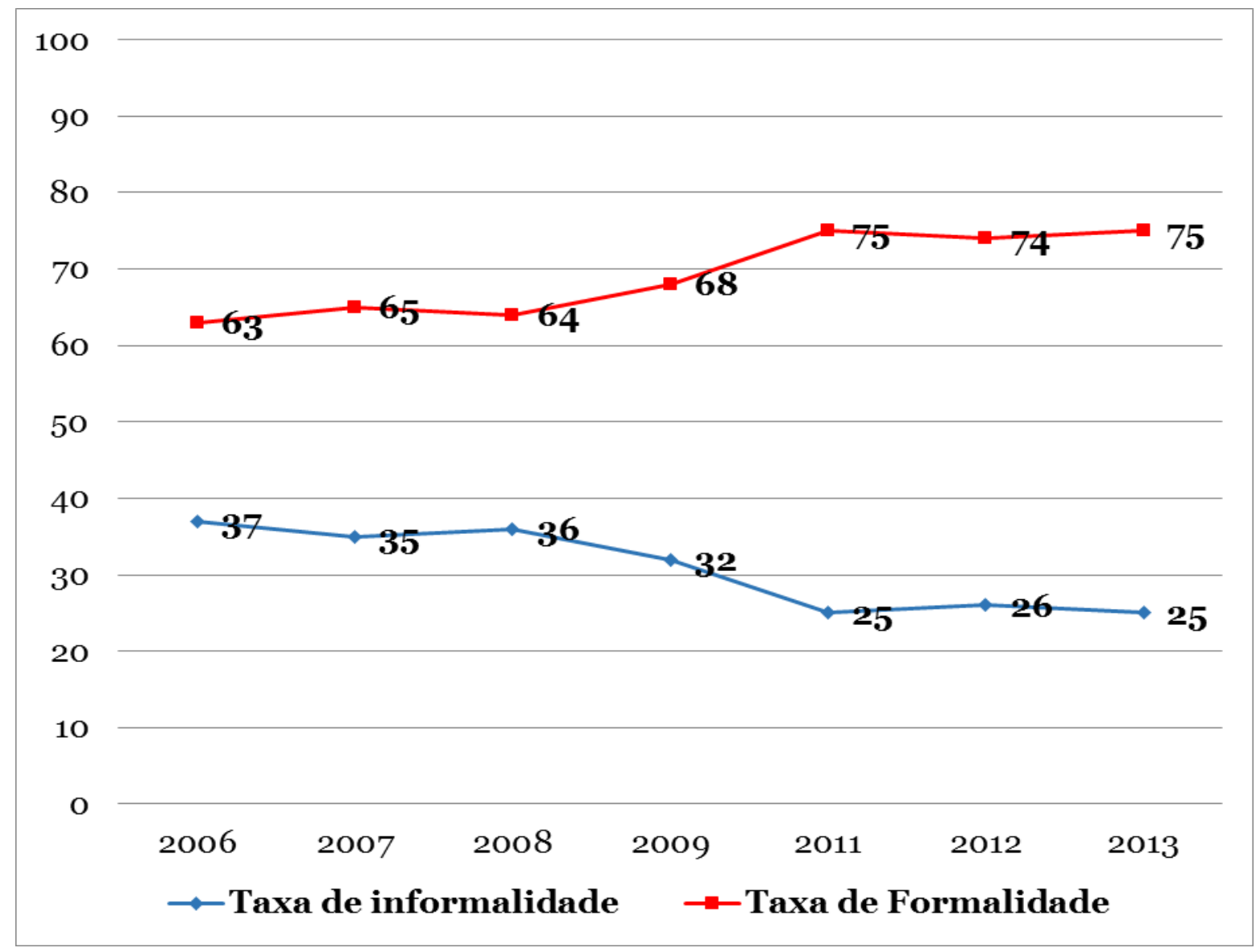

Fonte: Elaborado pelos autores com base nos dados da SST/SINE/SC, 2015.

Conforme o indicado no gráfico 3, de acordo com um retrato da dinâmica do mercado formal dos jovens de Santa Catarina de 2013, organizado pela SST/SINE/SC (2015), o setor econômico que mais gerou empregos foi o da indústria da transformação, com 36\%. Destacase ainda o comércio, com $28 \%$, seguido do setor de serviços, com uma taxa de $27 \%$. Esses três setores foram responsáveis por empregar mais de $90 \%$ dos jovens de Santa Catarina em 2013. 


\section{GRÁFICO 3: PARTICIPAÇÃO DOS JOVENS CATARINENSES NO MERCADO FORMAL DE TRABALHO POR SETORES ECONÔMICOS - 2013.}

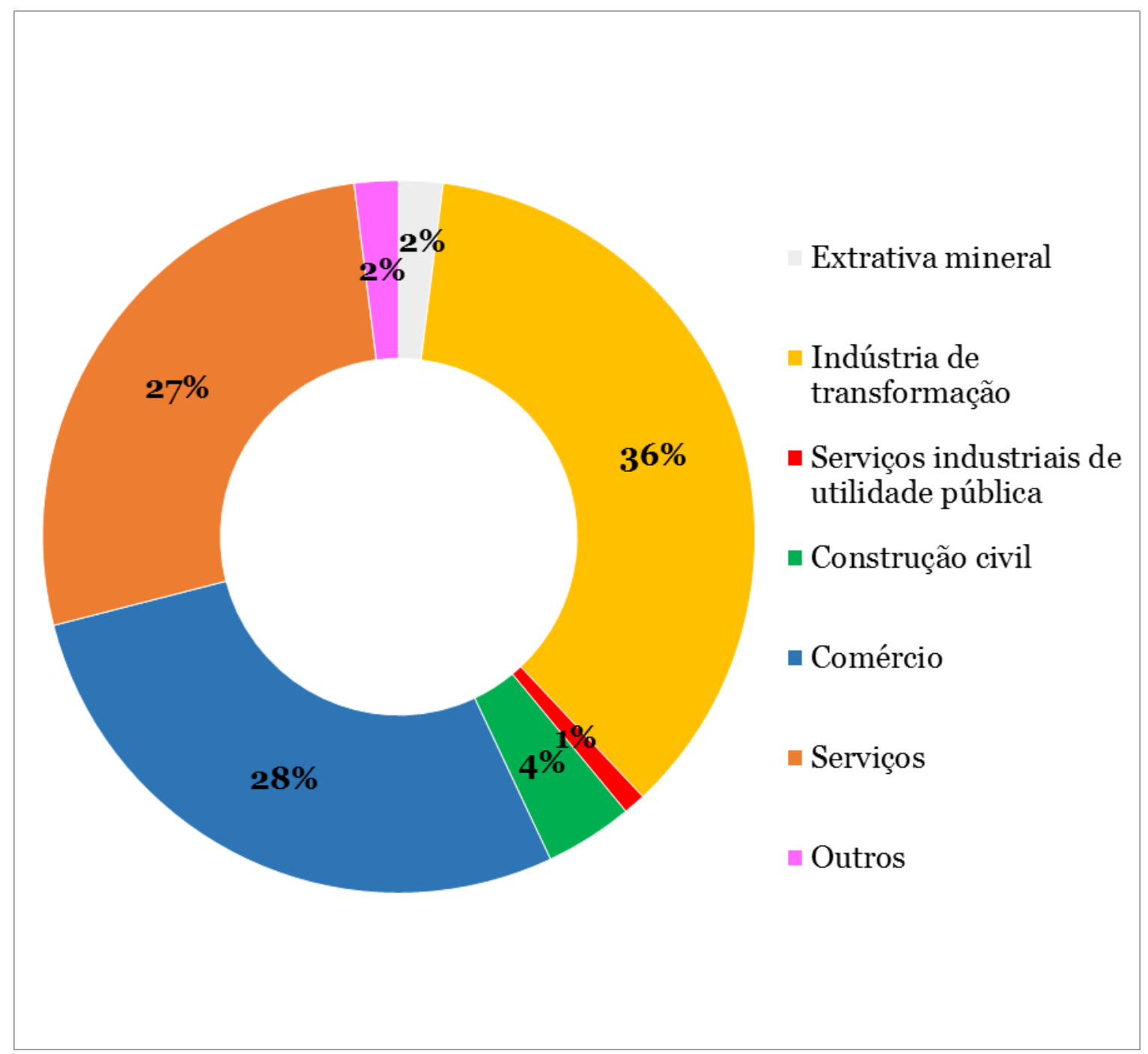

Fonte: Elaborado pelos autores com base nos dados da SST/SINE/SC, 2015.

$\mathrm{Na}$ busca da compreensão sobre o mercado de trabalho catarinense, percebe-se ainda a ausência de estudos mais aprofundados que relacionem a escolaridade da juventude trabalhadora do Estado catarinense. De acordo com dados do SST/SINE/SC (2015), para 2013, a maioria dos jovens trabalhadores de Santa Catarina possuíam o ensino médio completo: $52 \%$, outros $18 \%$ ainda não o tinham completado e, ainda, $11 \%$ tinham apenas o ensino fundamental completo. Apesar de poucos, convém ressaltar que 0,2\% foram considerados analfabetos. Aparentemente, a escolaridade do jovem trabalhador catarinense é baixa, afinal mais de $40 \%$ ainda não tinha o ensino médio completo. Evidente que isso acaba 
corroborando com postos de trabalhos mais precários e com um nível salarial muito abaixo da média.

A SST/SINE/SC (2015) ainda disponibilizou alguns dados salariais relativos às faixas etárias, mas com referência apenas para o ano de 2014. A título de exemplo, quanto menor a idade dos jovens, menor a remuneração. No momento da contratação, a maioria dos jovens até dezessete anos recebia pouco mais de um salário mínimo: $\mathrm{R}$ \$ 804,44. Já aqueles entre 18 e 24 anos chegavam a ganhar no ato da contratação, $R$ \$ 1.095,01. Esse valor corresponde a 85\% da média salarial de contratação geral do Estado. Conforme já descrito anteriormente, a inexperiência e os poucos anos de estudo fazem com que os jovens acabem recebendo menores salários.

\section{CONSIDERAÇÕES FINAIS}

A inserção do jovem no mercado de trabalho é um tema problemático. Infelizmente, a tendência é que o mercado de trabalho reproduza as hierarquias sociais preexistentes, limitando aos jovens de classe baixa, sobretudo, ocupações desvalorizadas, mal remuneradas e precárias. Além disso, as condições do jovem no mercado de trabalho no mundo, bem como no Brasil, são caracterizadas pelas desigualdades, tais como discrepâncias de gênero, grau de instrução, anos de experiência, localização dos postos de trabalho, atividades econômicas, dentre outras. A finalidade deste artigo foi apresentar um breve panorama sobre o jovem e o mercado de trabalho catarinense. Para isso, apresentamos os conceitos mais importantes relacionados ao mercado de trabalho para, em seguida, apresentamos as transformações no mundo do trabalho e a realidade da juventude catarinense.

A título de conclusão, cabe destacar os indicares que podem ser mais preocupantes. Os dados revelaram que PEA juvenil sofre uma queda, pois em 2006, 71,11\% dos jovens eram economicamente ativos, ao passo que em 2013, 68,68\% se enquadravam nesta categoria (queda de 3,28\%). Outro dado a ser considerado é com relação aos jovens trabalhadores das áreas urbanas, que passaram a 88,38\%, enquanto os jovens que pertencem a PEA e se situam no campo corresponder a 11,63\%. Isso também é resultado do processo da chamada concentração urbana e, como consequência, do êxodo rural. Tal retrato aponta que o jovem do campo se encontra sem perspectivas, buscando melhores oportunidades nos centros urbanos. 
Percebeu-se ainda uma queda na taxa de desemprego dos jovens em Santa Catarina, o que é muito positivo. Todavia, se observarmos as outras categorias, como por exemplo, a taxa de desempregos dos adultos, esta é de 3,2\% em 2013, ou seja, o desemprego entre os jovens é maior. Aliada a esta situação, quanto menor a idade dos jovens, maior é a taxa de desemprego: por exemplo, entre os jovens de 15 a 19 anos, essa taxa se eleva para $11,1 \%$. Isso mostra as dificuldades que os jovens encontram no mercado de trabalho.

Partimos da premissa que a juventude enfrenta inúmeras adversidades para inserção no mercado de trabalho e, quando inserido, acaba recebendo tratamento desigual se comparado a outros segmentos. A remuneração inferior seria uma destas disparidades. Os resultados assinalam que, além da remuneração mais baixa, a não formalização de um percentual significativo de jovens demonstram os óbices que o jovem enfrenta no mercado de trabalho. Outro dado significativo indica que a migração do jovem do campo para os grandes centros urbanos continua ocorrendo de maneira acentuada. Isto evidencia que a ausência de políticas públicas e/ou a ineficiência de ações governamentais implicam na saída do jovem do campo em busca de melhores oportunidades. Dado o histórico de ensino no interior do país, provavelmente esta força de trabalho que se desloca para os centros urbanos é precária no que tange sua qualificação e habilidades. Obviamente, isto acarreta em salários menores. Seria interessante a realização de pesquisas e estudos neste sentido para confirmar tal apontamento.

Outra questão que merece ser melhor examinada é o significativo percentual de jovens que trabalham na informalidade. Não restam dúvidas de que é necessário uma quantidade maior de estudos e análises para compreender a relação entre a juventude e o mercado de trabalho brasileiro. Além disso, o poder público e a sociedade civil organizada devem discutir alternativas para melhorar a inserção do jovem no mercado de trabalho. Tais políticas devem, além de permitir uma condição mais favorável, ser libertadora, no sentido de tornar o jovem independente e em boas condições para seu sustento. Não basta as empresas apenas seguirem a legislação, contratando estagiários e aprendizes. Se estas mesmas empresas fomentassem e/ou incentivassem a educação de qualidade, estariam formando não só mão-de-obra diversificada e habilitada, mas cidadãos qualificados e experientes. Outras pesquisas e estudos seriam importantes e necessários para a formulação de diagnósticos mais completos e detalhados sobre os problemas e adversidades que a juventude brasileira enfrenta quando da procura iniciar e avançar em suas vidas profissionais. 
No entanto, não restam dúvidas de que há desigualdades, no país e em Santa Catarina, quanto à inserção do jovem no mercado de trabalho. Evidentemente, existem especificidades quanto ao mercado de trabalho nacional e estadual/regional. Entretanto, a percepção é de que as desigualdades são semelhantes e apresentam um cenário desfavorável à inserção juvenil neste espaço. Diante deste cenário, a busca por soluções não parece ser algo simples e descomplicado, haja vista que este tema é complexo e problemático.

\section{REFERÊNCIAS BIBLIOGRÁFICAS}

ANTUNES. R. (2002). Adeus ao trabalho? Ensaios sobre as metamorfoses e a centralidade do mundo do trabalho. 8. ed, São Paulo: Cortez, 2002.

ALVES, G. Trabalho e sindicalismo no Brasil: um balanço crítico da "década neoliberal" (1990-2000). Rev. Sociol. Polít., Curitiba, 19, p. 71-94, nov. 2002.

ANTUNES. R.; ALVES, G. As mutações no mundo do trabalho na era da mundialização do capital. Educação \& Sociedade. Vol. 25, núm. 87, maio-agosto, 2004.

BEYNON, H. Globalização, neoliberalismo e direitos dos trabalhadores no Reino Unido. In: OLIVEIRA, Francisco de; PAOLI, M.C. (org) Os sentidos da democracia: políticas de dissenso e hegemonia global. 2ed. Petrópolis: Vozes, p.265-288, 1999.

CHESNAIS, F. A finança mundializada. São Paulo: Boitempo, 2005.

DICK, H. Gritos silenciados, mas evidentes: jovens construindo juventude na história. São Paulo: Loyola, 2003.

DIEESE - Departamento Intersindical de Estatística e Estudos Socioeconômicos. Séries Econômicas. Mercado de trabalho e Desemprego - 2001-2009. Disponível em: <http://www.dieese.org.br/ped/bd/mercadotrab.xml >

FREITAS, M. Juventude: Mapeando a situação: In; Curso de Verão ano XXI: Juventude: Caminho para outro mundo possível. /Jose Oscar Beozzo (org). São Paulo; Paulus, 2007.

HARVEY, D. Condição pós-moderna. 6. Ed. São Paulo: Loyola, 1996.

HARVEY, D. Espaços de esperança. Trad. A. U. Sobral; M. S. Gonçalves. São Paulo: Loyola, 2004.

HOLLOWAY, J. Mudar o mundo sem tomar o poder: o significado da revolução hoje. Trad. E. Sader. São Paulo: Viramundo, 2003.

IBGE - Instituto Brasileiro de Geografia e Estatística. Trabalho e Rendimento -Pesquisa Mensal de Emprego. 2015.2 Disponível em:<ftp://ftp.ibge.gov.br/Trabalho_e_Rendimento/Pesquisa_Mensal_de_Emprego/Notas_Tec nicas/transmetod.pdf $>$ Acesso em 01 de junho de 2015.

IBGE - Instituto Brasileiro de Geografia e Estatística. Pesquisa Nacional por Amostra de Domicílios - Síntese de Indicadores. 2015. Disponível em: <http://www.sidra.ibge.gov.br/pnad/pnadpb.asp?o=3\&i=P> Acesso em 01 junho de 2015.

MATTOSO, J. O Brasil desempregado: Como foram destruídos mais de 3 milhões de empregos no Brasil nos anos 90. Editora: Perseu Abramo, 2 ed. Agosto de 2000.

MARX, K. O capital: crítica da economia política (vol.1, tomo1). Trad. R.Barbosa; F.R. Kothe. 2 ed. São Paulo: Nova Cultural, 1985. 
MINISTERIO DO TRABALHO E EMPREGO. Políticas de emprego e renda para a juventude. 2013. Disponível em: http://www2.mte.gov.br/politicas_juventude/default.asp Acesso em: maio de 2013.

MÉSZÁROS, I. A Educação para além do Capital. São Paulo: Boitempo Editora. 2005.

OLIVEIRA, C. A. B. de; MATTOSO, J. E. L. (Org.). Crise e trabalho no Brasil: modernidade ou volta ao passado? São Paulo: Scritta, 1996.

ORGANIZAÇAO INTERNACIONAL DO TRABALHO. Trabalho decente e juventude no Brasil. [Brasília]: 2009. 220 p.

POCHMANN, M. Educação e trabalho: como desenvolver uma relação virtuosa? Educ. Soc. Campinas, vol. 25, n. 87, p. 383-399, maio/ago. 2004.

POCHMANN, M. O trabalho sob o fogo cruzado. São Paulo: Contexto, 1999.

POCHMANN, M. Situação do jovem no mercado de trabalho no Brasil: um balanço dos últimos 10 anos. 2007. Disponível em: http://www.emater.mg.gov.br/doc/intranet/upload/

RITSERT, J. Kleines Lehrbuch der Dialektik. Darmstadt: Wissenschaftliche Buchgesellschaft, 1997.

RAMALHO, J. R.; OLIVEIRA, R. V. de. A atualidade do Debate sobre Trabalho e Desenvolvimento. In.: Caderno CRH. Salvador, v. 26, n. 68, p. 211-215, Maio/Ago. 2013

SEADE - Fundação Sistema Estadual de Análise de Dados. (2015) Disponível em: http://produtos.seade.gov.br/produtos/ped/pedmv98/conceito.html Acesso em 01 de junho de 2015.

SECRETARIA NACIONAL DA JUVENTUDE. (2015) Disponível em: http://www.juventude.gov.br/ Acesso em 15 Fevereiro de 2012.

SST/DITE/SC - Secretaria de Estado da Assistência Social, Trabalho e Emprego/Diretoria de Trabalho e Emprego de Santa Catarina. O panorama dos jovens no mercado de trabalho catarinense: $\quad$ Boletim 2015. Disponível em: http://www.sst.sc.gov.br/arquivos/id_submenu/37/juventude_e_trabalho_em_sc_boletim_201 5.pdf Acesso em 01 de junho de 2015.

UNESCO. Políticas públicas de/para/com as juventudes. Brasília: UNESCO, 2004.

Recebido em 07 de outubro de 2017.

Aceito em 21 de novembro de 2017. 